\title{
Novo Professor Titular de Medicina Forense, Dr. Odon Ramos Maranhão
}

\begin{abstract}
A Redação
Aprovado por unanimidade em brilhante concurso realizado em maio de 1981, tomou posse solene como Titular da Cadeira de Medicina Forense o Professor Dr. Odon Ramos Maranhão

Reuniu-se a Congregação dos Professores no Salão Nobre, no dia 30 de setembro às 8,30 hs. $O$ novo titular foi introduzido no Doutoral pelos Professores Jose Ignácio Botelho de Mesquita, Ada Pellegrini Grinover e Armando Canger Rodrigues, da Faculdade de Medicina da Universidade de São Paulo.

A saudação foi feita pela Dra. Ada Pellegrin Grinover, que, "em nome da Congregação, recebe o sucessor, nesta Casa, de Amâncio de CarvalHo, alcântara machado, almeida Júnior e Costa JÚnior, com a certeza de que o Dr. Odon Ramos MARANHÃo será seu digno continuador, pois reúne as qualidades morais e intelectuais para tanto."

Em seu discurso de agradecimento, comovido, o Professor ODON relembra seus primeiros passos na carreira docente, e agradece a seus antigos mestres da Faculdade de Medicina, e aos colegas da Faculdade de Direito, que o ajudaram a conquistar o mais alto galardão do magistério superior, a titularidade da Cadeira de Medicina Forense na Faculdade de Direito da Universidade de São Paulo.
\end{abstract}

\section{O Novo Titular}

O Professor Odon RAMos MaRanhão nasceu em São Paulo, aos 23 de março de 1924. É filho de ODon CAVALCANTI Maranhão e de D. PaCífica Ramos. É casado com D. ZÉlia FÁvero Maranhão e tem quatro filhos.

$\mathrm{Fez}$ seus primeiros estudos em várias escolas estaduais da Capital, passou para o Colégio Bandeirantes e terminou seus estudos secundários no Anglo-Latino.

Matriculou-se posteriormente na Faculdade de Medicina da Universidade de São Paulo, tendo colado grau em 1953. 
Ainda estudante, fez estágios em diversas entidades médicas, conquistando especialização em vários campos da Medicina.

Estagiou, no Hospital das Clínicas da Faculdade de Medicina, na Clínica Psiquiátrica, na $1 .^{\mathrm{a}}$ Clínica Médica e na $10^{\mathrm{a}}$ Clínica Cirúrgica.

Na Faculdade de Medicina da Universidade de São Paulo fez estágio no Departamento de Medicina Legal, Cátedra do Professor FlamínIo FÁVERo; no Departamento de Histologia e Embriologia e no Departamento de Química Fisiológica.

Foi acadêmico residente no Sanatório Charcot; estagiou no Departamento Estadual da Criança - Instituto de Puericultura, e, sob o patrocínio do Centro Acadêmico Oswaldo Cruz, da Faculdade de Medicina, participou do trabalho da Liga de Combate à Sífilis.

Inicia, então, uma longa e profícua carreira profissional e docente, sem jamais afastar-se dos estudos.

Especializou-se em diversas áreas médicas e afins, como Psiquiatria, Eletrencefalografia, Medicina Psicossomática, Higiene Mental, Endocrinologia, etc.

Fez muitos cursos de extensão e aperfeiçoamento. No Instituto de Biotipologia Criminal cursou: Personalidades Psicopáticas, Perícia Psiquiátrico-Forense, Eletrencefalografia e Drogas Psicotrópicas.

$\mathrm{Na}$ Faculdade de Filosofia da Universidade de São Paulo cursou: Psicodiagnóstico de Rorschach, com aulas teóricas e práticas, debates e análise de protocolos de exames.

Cursou Psicologia Gestáltica e Topológica, na Sociedade de Psicologia de São Paulo e Psicodiagnóstico de Myra y Lopes, no Centro de Estudos de Franco da Rocha.

Fez o curso de Psicologia, Cadeira de Clínica Psiquiátrica, patrocinado pela Universidade de São Paulo e o de Personalidades Psicopáticas, patrocínio do Instituto de Biotipologia, do Manicômio Judiciário e Casa de Custódia.

Cursou ainda Semiologia Psiquiátrica, do Centro de Estudos de Franco da Rocha; Temas Práticos de Medicina Psicossomática, Medicina Psicossomática, ambos pelo Centro Acadêmico Oswaldo Cruz, e Orientação Educacional — Escola Universitária de S. Paulo.

Todos esses cursos de Psicologia, somados à sua grande experiência como Médico Psiquiatra propiciaram ao Dr. ODoN RAMOS MARANHÃo o registro profissional como Psicólogo Clínico, junto ao Ministério de Educação e Cultura, em fevereiro de 1964. 


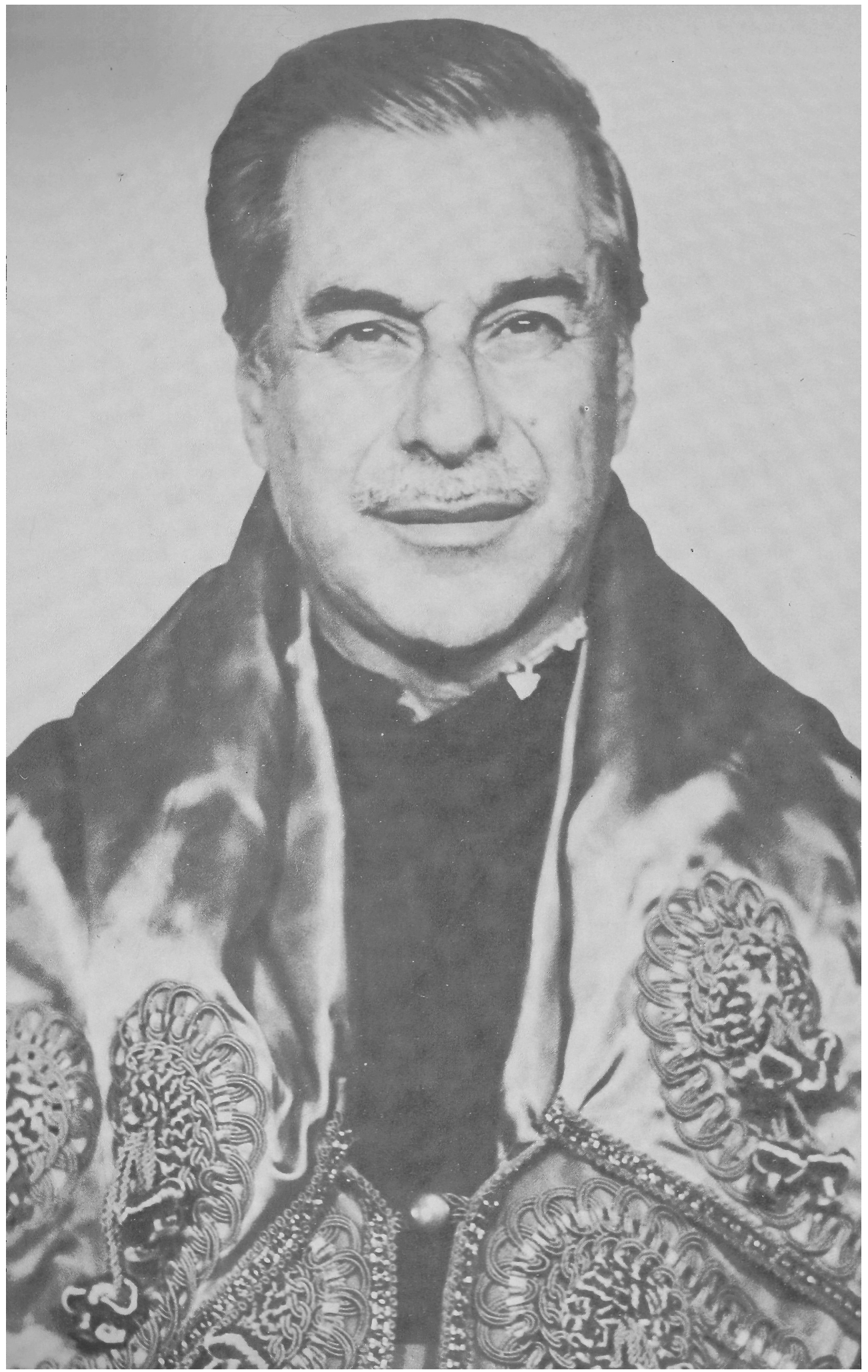


Professor Titular de Medicina Forense,

Dr. Odon Ramos Maranhãn 


\section{A Carreira Docente}

O Professor Odon RAmos Maranhão iniciou em 1955 sua carreira docente nesta Casa, como Assistente Extranumerário da Cadeira de Medicina Legal.

Em 1963, com a tese Elementos para a Perícia Médico-Legal na Avaliação da Periculosidade, conquistou a Livre-Docência. Em 1973, com aprovação plena no julgamento do memorial, torna-se Professor Adjunto.

E agora, com a tese Personalidades anti-sociais: aspectos da Controvérsia, conquista brilhantemente a Titularidade da Cadeira de Medicina Forense.

Já era Titular de Medicina Legal nas Faculdades de Direito de Itú, das Faculdades Metropolitanas Unidas e da Universidade Mackenzie.

É membro Titular da Academia de Medicina de São Paulo, (1969) e do Conselho Penitenciário (1981) ; e foi contemplado, entre outros prêmios, com a Medalha Anchieta, conferida pela Câmara Municipal de São Paulo, e por 4 vezes recebeu o Prêmio Oscar Freire de Criminologia, conferida pela Sociedade de Medicina Legal e Criminologia de São Paulo.

\section{Bibliografia}

A produção científica do novo Professor Titular é rica e abrange livros, monografias, teses, trabalhos premiados e trabalhos apresentados em Congressos.

Livros:

Curso Básico de Medicina Legal. São Paulo, Ed. Revista dos Tribunais, 1980.

Psicologia do Crime. São Paulo, Revista dos Tribunais, 1981 (no prelo). Trabalho premiado pela Sociedade de Medicina Legal e Criminologia em 1979.

Principios de Psiquiatria Forense (no prelo).

Manual de Sexologia Forense. São Paulo, Revista dos Tribunais, 1972. Teses:

Elementos para Perícia Médico-Legal na Avaliação da Periculosidade. Livre-Docência, 1963.

Personalidades anti-sociais: aspectos da controvérsia. Titularidade, 1981.

Trabalhos premiados:

A Perícia Médica no Livramento Condicional. 1964, Prêmio Oscar Freire.

Exposiçāo ao Sulfeto de Carbono. 1964. Prêmio Idealizadores do Sesi; em colaboração com o Professor Armando Canger Rodrigues.

I Inventário Multifásico da Personalidade de Minnesota. 1965. Prêmio Oscar Freire. 
Estudos de Criminologia. 1970. Prêmio Oscar Freire.

Em Congressos apresentou os seguintes trabalhos:

Delinqüência Neurótica. VI Congresso Brasileiro de Medicina Legal Recife, 1980.

Sistematização da Delinqüência Neurótica - IMESC - São Paclo, 1980.

$A$ "Classificação Natural" e a "Triagem" de Sentenciados - 2.0 Congresso Brasileiro da Administração Penitenciária - São Paulo, 1980.

Nos diversos "Congressos Brasileiros de Medicina Legal", realizados em diferentes cidades brasileiras, apresentou:

Consideraçōes sobre o Código de Processo Ético-Disciplinar - 5., Belo Horizonte, 1978.

O Estado Perigoso. 4., São Paulo, 1974.

Delinqüência Essencial: um controvertido diagnóstico. 4., São Paulo, 1974.

Os indices Delinqüenciais no Inventário de Minessota. 4. ${ }^{\circ}$, São Paulo, 1974.

Capacidade de Imputação: resultados de 300 perícias. $3 .^{\circ}$, Belém, 1971.

O Eletrencefalograma em delinqüentes. 2. ${ }^{\circ}$, Curitiba, 1969.

O Tríptico Lombrosiano: um problema que ressurge? 2. ${ }^{\circ}$, Curitiba, 1969.

Sinais excludentes de simulação nas Lombalgias Espondilogênicas-Acidentárias. 2., Curitiba, 1969. Em colaboração com o Professor Armando Canger Rodrigues.

\section{Atividades docentes}

Na Faculdade de Direito da Universidade de São Paulo, o Professor Odon MARANhão é regente do curso de Medicina Legal desde 1964, e rege também o curso de Criminologia, do IX Semestre - Área de Direito Penal, desde 1972, ambos a nível de graduação.

É Professor Titular, regente de Medicina Legal nas Faculdades Metropolitanas Unidas e na Universidade Mackenzie.

Em cursos de pós-graduação, leciona Criminologia, nesta Faculdade, e Psicopatologia Forense, na Faculdade de Medicina da. Universidade de São Paulo, Área de Psiquiatria.

O Professor Odon MARANHÃo pronunciou diversas palestras e deu alguns cursos avulsos sobre os mais variados temas de sua especialidade, em Faculdades de Direito e de Medicina:

Principios de Psiquiatria F'orense

Delinqüência Jcvenil

Problemas médico-legais no tratamento cimirgico de transsexuais

Omissão de socorro

Dinâmica do ato criminoso

Personalidade psicopática e personalidade delinqüente

Violência sexual

Aborto e ética

Anulação de casamento, e muitos outros. 
Participou de Bancas Examinadoras de Concursos na Faculdade de Direito, na de Medicina, no Instituto de Psicologia, no Instituto de Biociências, todos da Universidade de São Paulo, na Escola de Sociologia e Política, na Faculdade de Medicina de Mogi das Cruzes e Escola Paulista de Medicina.

É membro Titular da Academia de Medicina de São Paulo, sócio fundador da Associação Paulista de Higiene Mental e Psiquiatria Infantil, e do Centro de Estudos Criminológicos do Instituto de Biotipologia Criminal.

Pertence às seguintes entidades: como sócio efetivo, da Associação Paulista de Medicina, do Centro de Estudos de Franco da Rocha, da Sociedade Rorschach Internacional e da de São Paulo; como sócio titular, pertence à Sociedade de Psicologia de São Paulo, à Sociedade de Medicina Legal e Criminologia, à Sociedade Paulista de História da Medicina e à Associação Psiquiátrica de São Paulo.

É membro Pleno da Sociedade Internacional de Hipnose e da Sociedade Paulista de Medicina Social e do Trabalho.

\section{A posse}

Dia 30 de setembro, às 20,30 horas, reuniu-se em sessão solene a Congregação dos Professores da Faculdade de Direito para recepcionar o Novo Titular de Medicina Forense, Professor Dr. ODON RAMOS MARANHÃo.

Dando início à cerimônia da posse, o Diretor, Professor Antonio Chaves, designou a Professora ADA PeLlegrini Grinover e os Professores IgNácio Botelho DE Mesquita e CANGER RODRIGUES, para introduzirem o novo titular no recinto, dizendo em seguida:

"Eminentes colegas, minhas senhoras, meus senhores.

É com satisfação que a Faculdade de Direito se engalana hoje para dar posse ao novo Titular ODON RAMOS MARANHÃo.

Dentre as personalidades que não puderam apresentar-se, algumas quiseram demonstrar sua presença espiritual, enviando mensagens, como a da Professora ODETE LOURENÇÃo VAN KowLC do Instituto de Psicologia:

"Impossibilitada de comparecer, congratulo-me com o prezado amigo pela nova conquista na carreira universitária."

Do Dr. DJalma Lúcio Gabriel Barreto, Chefe de Gabinete, recebemos o seguinte telegrama: 
"Professor ANTonio Chaves, Diretor da Faculdade de Direito do Largo São Francisco. Motivo de força maior impede-me de comparecer na solenidade de posse do Professor ODON RAMOs MARANHÃo, assim, deixo aqui consignados meus efusivos cumprimentos ao ilustre Professor pela justa investidura."

Do Dr. Alvim Passos:

"Professor Odon Ramos Maranhão, Faculdade de Direito da Universidade de São Paulo. Impossibilitado de comparecer, nesta importante e justa posse, nossas homenagens."

É portanto com a maior satisfação que passo a palavra à Professora ADA PELLEGRINI GRINOVER, que foi incumbida pela Congregação de saudar o novo titular.

A Professora AdA Pellegrini GRINover, em brilhante discurso, enalteceu as grandes qualidades de mestre e especialista em diversas áreas afins à Medicina Legal, virtudes inerentes ao Professor ODoN, especialidades como Psicologia Clínica, Psiquiatria, Eletrencefalografia, Medicina Psicossomática, Higiene Mental, Endocrinologia e tantas outras, "que abriram-lhe os caminhos que desembocariam no estudo interdisciplinar, como o é a sua cadeira nesta Casa".

Ao chegar a Titular de Medicina Legal, o Dr. ODoN RAmos MARANHÃo atinge o grau máximo de sua carreira docente. "Galardão mais alto não pode haver, e o novo Professor Titular o alcançou por seus indiscutíveis méritos de homem e de estudioso, após longo e áspero caminho, que lhe temperaria o espírito, até levá-lo à conquista da Cátedra de Medicina Legal na Faculdade de Direito da Universidade de São Paulo".

O Professor ODON agradeceu a homenagem com um comovente discurso, lembrando cada um dos que o ajudaram a galgar os degraus da carreira universitária, seus antigos mestres da Faculdade de Medicina, onde se formou, Professores ARNALDo Amado Ferreira e Flamínio Fávero, e aos mestres desta Casa Costa Júnior, Manoel Pedro Pimentel, NaIr Lemos GonÇALVES e ADA PELLEGRINI GRINover, por seu formoso discurso.

Continuando sua exposição, faz uma reflexão sobre os graves problemas da Medicina Legal contemporânea e passa em revista alguns de seus aspectos mais importantes, ressaltando o caráter interdisciplinar de sua cadeira, frisando "o que a caracteriza como Ciência e define sua individualidade 
é um particular corpo de doutrina, amoldado aos interesses do Direito, respeitada a natureza médica lato sensu, o espírito jurídico e o sentido social".

E finaliza agradecendo a seus familiares e inúmeros amigos, expressando seu sentimento mais profundo: "Volto-me para Aquele que me guia por caminhos jamais antevistos, leva-me a lugares não sonhados e cobre a minha vida de bênçãos, o meu Deus e Senhor, no tempo e na Eternidade".

\section{Saudação da Professora Ada Pellegrini Grinover}

Mal se apagaram as luzes deste Salão Nobre após a cerimônia de minha posse e eis que o Senhor Diretor, Professor Antônio Chaves, me atribui a honrosa incumbência de receber, em nome da Douta Congregação, o novo Professor de Medicina Legal, dr. Odon Ramos Maranhão. O mesmo ambiente, os mesmos trajes, a mesma solenidade. Tudo evoca, a meus olhos, outra cerimônia, tão recente.

Creio ser esta a única justificativa para a minha designação: a última dos empossados a receber o mais novo Titular desta Casa, numa mescla de emoções que se entrelaçam. O orgulho, o respeito, a gratidão de quem chega; a alegria, o júbilo, o congraçamento de quem acolhe. Eu represento aqui como que a ponte entre o recipiendário e os receptores. Não tão antiga a ponto de ter olvidado os sentimentos daquele. Já nestes integrada para manifestar seu estado de espírito.

$\mathrm{E}$ assim, em nome da Congregação festivamente reunida, tenho a honra de dar as boas vindas ao Professor Odon Ramos Maranhão, sucessor, nesta Casa, de Amâncio de Carvalho, de Alcântara Machado, de Almeida Júnior e de Costa Júnior.

Elevada é a responsabilidade de suceder a tão eminentes Mestres, mas profunda é a certeza de que o dr. Odon Ramos Maranhão será seu digno continuador, pois reúne as qualidades morais e intelectuais para tanto.

Traz ele no sangue a vocação para o ensino. Odon Cavalcanti Maranhão e Pacífica Ramos, seus pais, foram ambos Professores Primários, e lhe inculcaram, desde pequeno, o espírito de sacrifício, de dedicação e de abnegação que plasma os verdadeiros mestres. Sua fibra e firmeza de caráter patentearam-se cedo: ainda no III Ano da Faculdade de Medicina da Universidade de São Paulo, acometido de grave distrofia bilateral da córnea, quando lhe restava apenas $1 / 10$ de acuidade visual e os médicos o aconselhavam a deixar o curso, nele 
insistiu, com enormes sacrifícios pessoais e à custa de sua força de vontade, logrando concluí-lo, sem interrupção, com o desdobramento dos $3 .^{\circ}$ e $4 .^{\circ}$ anos.

Quem o iniciou na carreira universitária foi o Dr. Arnaldo Amado Ferreira, Professor de Medicina da Universidade de São Paulo e um dos fundadores das Faculdades de Medicina de Santos e da Faculdade de Direito de São José e de São Bernardo do Campo. Pela mão do saudoso Mestre ingressou o Dr. Odon Ramos Maranhão, ainda estudante do $5 .^{\circ}$ ano, como Técnico de Laboratório, na Faculdade de Medicina da Universidade de São Paulo, ali forjando seu interesse pela Medicina Legal. Nessa época, contraiu núpcias com Dona Zélia Fávero Maranhão, já formada em pedagogia e que ainda se licenciaria em língua e literatura francesas pela Sorbonne, concluindo o curso de Mestrado pela Universidade de Nancy. Soube Dona Zélia conciliar à perfeição seus interesses culturais com a bela missão de companheira e de mãe, apoiando e estimulando o esposo, dando-lhe serenidade e tranqüilidade, incentivando os filhos e encaminhando-os, com seu exemplo, pela via árdua e gratificante do estudo e do trabalho. Após a formatura, assumiu o Dr. Odon Ramos Maranhão o cargo de assistente do Prof. Flamínio Fávero, seu outro paraninfo, e finalmente, após o interstício de dois anos, então necessário - e pelo qual o Prof. Almeida Júnior aguardou o novo assistente - ingressou nesta Casa, nela continuando, depois, como assistente do Prof. João Baptista de Oliveira e Costa Júnior, a quem agora sucede na cátedra, vaga por força da cega norma da aposentadoria compulsória.

Cedo demonstrou seus pendores como Professor de Medicina Legal. Aliás, não se satisfizera ele com o título de Médico, mas buscara também o de psicólogo clínico, registrando-se no MEC nos albores da regulamentação da profissão, ainda em 1964. Outras especializações - em Psiquiatria, Eletrencefalografia, Medicina Psicossomática, Higiene Mental, Endocrinologia e tantas outras - abriram-lhe os caminhos que desembocariam no estudo interdisciplinar por excelência, na disciplina - encruzilhada, que é a medicina legal.

Desta, teve oportunidade de escrever Oliver Schroeder Jr.:

“É preciso fundir as forças isoladas do direito e da medicina em um novo empenho cultural, num empreendimento intelectual interdisciplinar."

"A nova disciplina "pois nova é, nesse enfoque" precisa integrar os conhecimentos jurídicos 
e médicos para prover capacidades que atendam simultaneamente à Justiça e à Saúde."

Capacidade que atenda simultaneamente à Justiça e à Saúde é essa, moldada na vocação e no longo preparo do Professor Odon Ramos Maranhão que, no primeiro capítulo de seu Curso Básico de Medicina Legal, coloca a nova disciplina, autônoma, como "matéria interdisciplinar que forma especialistas para atender aos interesses comuns da Medicina e do Direito."

Assim, nessa senda claramente delineada no cipoal do conhecimento humano, Odon Ramos Maranhão trilhou o seu caminho luminoso, que se iniciara nos bancos acadêmicos, desde o aprendizado como Técnico de Laboratório da Faculdade de Medicina. E, após alcançar os títulos de Livre Docente e Adjunto nesta Casa - sempre com aprovação plena - bem como sagrar-se Professor Titular de Medicina Legal da Faculdade de Direito de Itu, das Faculdades Metropolitanas Unidas e da Faculdade de Direito da Universidade Mackenzie, chega finalmente o Dr. Odon Ramos Maranhão ao cargo máximo da carreira, nesta Faculdade. Galardão mais alto não pode haver, e o novo Professor Titular o alcançou por seus indiscutíveis méritos de homem e de estudioso, após longo e áspero caminho, que lhe temperaria o espírito, até levá-lo à conquista da cátedra de Medicina Legal da Faculdade de Direito da Universidade de São Paulo. Verdadeira conquista, ao cabo de brilhante concurso em que revelou a seriedade do preparo, o rigor científico da formação, as multifárias facetas do homem aberto às tendências interdisciplinares da ciência moderna. E disso eu sou testemunha, pois me foi dada a elevada honra de integrar a Comissão Examinadora, presidida pelo Prof. Manoel Pedro Pimentel e composta pelos Professores Holdemar Oliveira de Menezes, Armando Canger Rodrigues e Marco Segre, a qual indicou unanimemente o candidato, aprovando-o com média 9,26 .

Muitos outros títulos do Professor Odon Ramos Maranhão poderiam ser mencionados: Prêmios e Medalhas - dois Prêmios Oscar Freire de Criminologia e um de Medicina Legal, Medalha Anchieta, Medalha Cultural Oscar Freire; os diversos livros publicados, alguns didáticos, outros científicos, vários já esgotados; os inúmeros trabalhos apresentados em Congressos; as Comissões Examinadoras de que fez parte; os cursos, conferências e palestras que ministrou; os cargos eletivos em que foi investido e as comissões científicas que integrou; suas atividades como psiquiatra concursado no Departamento de 
Psiquiatria do Hospital das Clínicas da Universidade de São Paulo e como membro do Conselho Penitenciário, e tantos e tantos outros, a demonstrarem uma inesgotável fonte de energia e uma dedicação ímpar e serena.

Entre todos, contudo, o título mais ambicionado, o que mais sacrifícios lhe custou, o que transcende o significado imediato de uma conquista, é o de Professor Titular desta Casa. Ainda há pouco, em cerimônia igual a esta, ao agradecer a saudação recebida do Prof. Manoel Gonçalves Ferreira Filho, em nome desta mesma Congregação, quando de minha posse solene, dizia eu :

"Ser professor desta casa significa a inserção concreta nessa Douta Congregação, ou seja a participação integral e definitiva, pelo cargo mais elevado da carreira, em uma instituição secular. Instituição que é uma realidade jurídica permanente, estável em sua atuação e em suas tradições, e ao mesmo tempo dinâmica e variável, para adaptar-se às necessidades mutantes. Essa instituição tem entre seus valores fundantes os melhores valores da própria sociedade: o humanismo, o vigor e a coragem das idéias, a luta pelo direito, pela justiça, pela liberdade. Este é seu idealismo de ontem e de hoje. Por essas idéias morreu-se no passado; para essas idéias continuamos a viver.

Mas uma instituição somente sobrevive quando os que a integram se identificam com os princípios de sua existência e com as suas finalidades últimas. A instituição pressupõe a união de todos em torno do objetivo comum, pela adesão e pela colaboração, formando todos um só corpo, voltado à execução de seu ideário. Por isso, a instituição pode soçobrar frente às paixões dos homens, quando estes se afastam da conduta necessária à preservação do espírito institucional. Cabe a nós cimentá-la pelas crenças e pelas realizações, para que ela permaneça, vigorosa e altaneira, resistindo aos ataques externos e internos dos que a vilipendiam. O importante é termos sempre presentes os valores fundamentais dessa instituição, conjuntamente congregados e voltados à consecução de seus fins, para que possa ela sobreerguer-se acima das fraquezas de alguns, graças ao esforço de muitos." 
Essas palavras, que ainda há pouco eu proferia como recipiendária, repito-as agora, como receptora. Destinam-se a quem ingressa na instituição e a quem nela queira permanecer, cônscio do verdadeiro espírito da Escola.

Eis que o ideário de quem entrava se transmuda na crença de quem fica. Que sejam essas as nossas palavras de boas vindas, caro Professor Odon Ramos Maranhão. Que sua chegada o integre na Congregação com um sopro de alento, um prenúncio de fé. Que sua chegada seja um ponto de partida.

\section{Oração do Professor Odon Ramos Maranhão}

Convocado pelo Professor Doutor Antonio Chaves, DD. Diretor da Faculdade de Direito da Universidade de São Paulo, para uma sessão solene da Douta Congregação, em que se dará posse ao novo Professor de Medicina Legal, dirijo-me ao Largo de São Francisco. Entrando no histórico prédio da "velha e sempre nova Academia", sinto-me em verdadeiro devaneio, vindo-me à lembrança, desordenadamente, dados da sua história: sua criação, no período do Brasil-Império; as campanhas abolicionistas; a implantação da República; a luta constitucionalista...

Com especial colorido relembro os Mestres da Ciência de Ambroise Paré e PaUlo ZaCchia:

- Amâncio de CARvalHo, que aqui lecionou por mais de quarenta anos e adaptou a antiga Medicina Pública aos moldes da Miedicina Legal européia;

- AlCÂNTARa MACHADo, o jurista que foi acatado como "médico honorário", devido aos seus amplos conhecimentos e nos legou, entre muitas outras produções notáveis, o Anteprojeto do Código Penal de mil novecentos e quarenta;

- ANTonio FerReira dE Almeida JÚnIoR, eminentemente um "Professor", tendo lecionado em cursos primários, secundários e superiores, em Faculdades de Medicina e Direito, o didata por excelência;

- JoÃo B. DE Oliveira e Costa JÚnior, Professor Emérito desta Casa, ex-Diretor da Faculdade de Medicina de Sorocaba e Vice desta Faculdade, associou-se ao trabalho didático de seu antecessor e o livro Lições de Medicina Legal tornou-se o texto mais usado no ensino dessa Disciplina em todo o território nacional.

Alcançando a antecâmara da "Sala das Becas", passo em frente à chapeleira, vejo minha imagem refletida no espelho 
e um arrepio percorre o meu corpo: agora me dou contas de que o Professor a ser empossado sou eu mesmo e sinto esmagar-me o peso da responsabilidade do cargo e da tradição cultural sesquicentenária das Arcadas.

Depois de aberta a sessão pelo Diretor e cumpridas as formalidades de praxe, sou recebido na Congregação com $o$ formoso discurso da Professora ADA PELlEGRINI GRINover, Chefe do Departamento de Medicina Forense e Membro da Comissão Julgadora do Concurso para Professor Titular de Medicina Legal, realizado em maio passado, a quem agradeço comovido.

Saindo, então, do meu devaneio e refazendo-me do susto, começo a refletir sobre os graves problemas de Medicina Legal contemporânea e passo em revista alguns de seus aspectos mais importantes.

Desde logo, volto-me para o caráter interdisciplinar que sempre revestiu essa Ciência, ocupada em reunir conhecimentos de vários campos relacionados ao Homem e à Saúde, para bem servir à Justiça. Verifico não poder considerá-la uma especialidade, posto que se socorre da colaboração de vários profissionais. Já em 1974, LEON DÉRoBERT, na França e OLIVIER SCHROEDER nos Estados Unidos, a consideravam uma "capacidade" para resolver os problemas da Saúde e do Direito. E foi esse o conceito que adotei ao analisar os novos rumos da Medicina Legal em 1977 e posteriormente nas edições didáticas de 1978 e 1980.

O que a caracteriza como Ciência e define a sua individualidade é um particular corpo de doutrina, amoldado aos interesses do Direito, como se infere dos preciosos ensinamentos do Professor Costa JúnIoR, respeitada a natureza médica "lato sensu", o espírito jurídico e o sentido social, a que já fazia. referência o saudoso mestre de Strassburg, Charles Simonin.

Dentro dos limites desses parâmetros, urge uma reformulação dos cursos pós-graduados e do acesso à carreira docente, para se abrir oportunidades a profissionais não médicos, que desejam se dedicar à pesquisa e ao ensino dessa fascinante e multiforme ciência interdisciplinar.

É com satisfação que registro ter esta Faculdade de Direito recentemente admitido, mediante concurso de provas e títulos, Professor Assistente do Departamento de Medicina Forense, uma bacharel. Da mesma forma, verifico com entusiasmo estar a Faculdade de Medicina da Universidade de São Paulo promovendo concurso de Livre Docência em Deontologia Médica, pela 
primeira vez como Disciplina, tendo inscrito candidato que é advogado e filósofo.

Se é verdade que a Perícia permanecerá sempre como atividade profissional específica, não é verdade menor que a investigação científica e a atividade didática possam ser exercidas por vários profissionais convenientemente preparados, dentro do novo conceito de Medicina Legal.

Por outro lado, reconheço que o ensino dessa Disciplina nas Faculdades de Medicina e nas Faculdades de Direito se diversificará no aspecto formal, no método e no objetivo. 0 médico será o Perito e precisa saber examinar, registrar, concluir, informar, enquanto o advogado - e conseqüentemente - jurista - há de saber inquirir, criticar e até contestar a matéria médico-legal.

Até hoje não consegui entender a inclusão, pelo MEC, da Medicina Legal no elenco das "disciplinas facultativas", de que trata a Resolução 3/72. Quando a Douta Congregação desta Casa tratou desse assunto, na qualidade de Representante dos Livre Docentes, tive o ensejo de lembrar que só se forma um bom profissional com o concurso de amplo elenco de Disciplinas e não somente a custa de excepcional Mestre, atuando isoladamente. Tive a satisfação de ver acolhido este modesto argumento, tendo sido preservado o ensino da Medicina Legal nesta Faculdade de Direito, agora oferecido também em cursos pósgraduados, já reconhecidos pelo Ministério de Educação e Cultura.

Os menos avisados têm confundido a medicina pericial com o amplo campo da medicina forense, tomando a parte pelo todo. Contudo, essa é a Medicina Legal de "consumo diário", posto que os exames de interesse jurídico ocorrem a todo instante e em todo lugar. Também, essa é a parte mais estável, pois lida com matéria estabelecida, doutrina firmada e direito constituído.

Bem mais complexos são os "problemas de fronteira", as "questões-limites". A título de exemplo, cito a própria Deontologia Médica, que - primeiramente ensinada em caráter "moralista" e passando a uma fase de regulamentação pelo Código de Ética Médica - agora propõe novos problemas. Até aqui se tem cogitado dos "deveres do médico", partindo-se do pressuposto de que se trata de uma "profissão liberal". Mas o médico contemporâneo é basicamente um assalariado, o que modifica a sua posição na sociedade. De certa forma ela passa a se confundir com inúmeras outras atividades. Cogita-se - 
e muito - dos deveres do médico em relação aos demais, ficando esquecido o que se the deve, ou seja, daquilo a que tem direito.

Em 1975, o Professor Genival Veloso De Franç, da Universidade Federal da Paraíba, publicou o livro Direito Médi$c o$, no qual preconiza seja regulamentado por legislação própria o exercício médico-profissional, "mas também tudo aquilo a que estão obrigadas as pessoas ante a Medicina". Pois esse "Direito Médico", que um dia será lecionado a acadêmicos de Medicina e de Direito, surgirá sob a inspiração da Medicina Legal Contemporânea.

Vivemos um período de criminalidade crescente e algumas medidas estão surgindo, como os Anteprojetos de Novos Códigos Penal e Processual Penal, elaboração de Lei das Execuções Penais, a reforma do Sistema Penitenciário. É bem verdade que a muitos profissionais penitenciários falta uma visão biopsíquica da personalidade dos infratores. Muitas tentativas surgiram para suprir essa lacuna e já em 1964, o preclaro Professor e ex-Reitor Miguel REALe, na Secretaria da Justiça, criava a Escola de Administração Penitenciária, vinculada ao então Departamento dos Institutos Penais do Estado.

Pois esse enfoque "biopsíquico" pode e deve ser atribuição da "criminologia clínica", que não se confunde com a "sociológica", nem com a "penológica". Matéria essencialmente médica que é, integra o Departamento de Medicina Forense, como bem estabeleceu a Reforma Universitária. Falta, porém, emprestar-lhe a estrutura de disciplina autônoma, o que só contribuirá para o aprimorar do ensino desta inigualável e pioneira Faculdade de Direito.

A psicologia judiciária, bem como a psicopatologia forense, são partes integrantes da Medicina Legal. Elas não interessam aos profissionais que se dedicam à atividade curativa ou preventiva, mas são preciosas para a boa distribuição da Justiça. Interessam ao Direito Civil, Penal, Processual e Trabalhista. A primeira (psicologia judiciária) tem estado quase em ostracismo, havendo falta de manuais atualizados e publicações técnicas ordenadas, obrigando os interessados a trabalhosas consultas bibliográficas. A Reforma Universitária a incluiu no Departamento de Medicina Forense e, creio, deverá ser organizada em disciplina autônoma.

A segunda (psicopatologia forense), ensinada na Faculdade de Medicina em curso pós-graduado, conta com poucos especialistas em nosso meio, o que leva o Judiciário a servir-se de clínicos da psiquiatria para atender aos interesses forenses. 
Uma integração de todos esses campos científicos e outros não mencionados - talvez exija uma estrutura de pesquisa e ensino muito mais ampla do que um simples Departamento. Lembro-me, então, do alto nível cultural, da ampla produção científica e do renome internacional do Instituto "Oscar Freire", que o eminente Professor Emérito FLAMÍNIo FávERo organizou e dirigiu por algumas décadas, à sombra protetora da Faculdade de Medicina da Universidade de São Paulo. Pois esse Instituto, com toda a sua tradição, envolvendo nomes brilhantes como VEIGA DE CARVAlHo e CANGER RODRIGUES, entre muitos outros, bem poderia ser o precursor de um Instituto Universitário de Medicina Legal. Sei que isto é sonho, mas muitos sonhos um dia se tornam realidade.

Vindo a ocupar o alto cargo em que agora sou investido, verifico não ser possível aqui chegar, sem o concurso de um sem-número de fatores, entre os quais sobressaem a influência e a colaboração de Mestres, familiares e amigos. Experimento, por isso, profundo sentimento de gratidão, impossível de ser silenciado.

Reverencio e homenageio nesta hora meus antigos mestres da Faculdade de Medicina, onde me formei e onde iniciei com os caros amigos Professores ARNaldo Amado Ferreira e FlaMínIo FÁVERo a minha carreira docente. Agradeço o convívio e os ensinamentos dos excelentes Professores da Faculdade de Direito da Universidade de São Paulo, que - recebendo-me como simples Instrutor - auxiliaram-me a chegar a este posto. Entre muitos nesta Casa, agradeço de modo especial ao Professor ALMEIDA JúNIOR (in memoriam) e aos Professores Costa Júnior, Miguel Reale, Manoel Pedro Pimentel, Nair Lemos Gonçalves, AdA PeLlegrini GRINOver e aos meus examinadores dos Concursos de Livre-Docência, de Professor Adjunto e de Professor Titular. Estendo, particularmente, esses agradecimentos à Digna Secretária - DRINADIR CoElHo - sempre atenta a nossos problemas - e aos eficientes Auxiliares do Departamento: IRENe B. MUAKAD, José LOPES Zarzuela, Miguel Falci e José Glauco Bardella.

Sou grato - e muito - a meus familiares e meus filhos, que me compreendem e apóiam, e especialmente à minha esposa - Professora Zélia FáVERo MARANHÃo - a quem, depois de vinte e nove anos de casamento, posso continuar repetindo afetuosamente: "hoje mais do que ontem e menos do que amanhã”.

Aos amigos, tantos, de tantas origens e procedências, estendo um abraço agradecido. 
A meu Diretor, Professor Antonio Chaves, a quem devo tantas atenções, minha gratidão. Aos colegas, companheiros, Diretores e Reitores da Universidade Mackenzie e das Faculdades Metropolitanas Unidas, bem como do Instituto de Psicologia da Universidade de São Paulo e dos Estabelecimentos Penitenciários do Estado, meu agradecimento.

Deixei para o fim, propositadamente para o fim, o meu sentimento mais profundo, que expresso numa atitude de verdadeiro culto: Volto-me para Aquele que me guia por caminhos jamais antevistos, leva-me a lugares não sonhados e cobre a minha vida de bênçãos, o meu Deus e Senhor, no tempo e na Eternidade.

\section{Palavras do diretor, Professor Antonio Chaves encerrando a sessão solene}

Preclaros Membros da Congregação, senhora Secretária, eminente colega e amigo Professor CANGER RoDRIGUES, senhores estudantes, minhas senhoras e meus senhores:

Acabamos de ouvir duas peças oratórias, cada uma com características peculiares. A da Professora ADA PELLEgRINI GRINOVER no seu estilo impecável, na sua frase bem construída, fazendo uma saudação, ao mesmo tempo enternecedora e comovente e a do Professor recém-empossado, com laivos de literatura, muito sentimento e recordações que a todos nós nos deixam empolgados.

Da oração da Professora AdA Pellegrini Grinover, quero repetir algumas expressões que ficaram mais gravadas. nidade."

"O mesmo ambiente, os mesmos trajes, a mesma sole-

O mesmo ambiente sim, os mesmos trajes, as mesmas solenidades.

Mas quanta diferença no decurso de poucos anos entre a posse de um Professor e a posse de outro Professor que o saúde na mesma disciplina!

É claro e não nos foi dado acompanhar no exemplo típico na cadeira de nosso homenageado de hoje, as sucessivas posses de Amâncio de Carvalho, Alcantara Machado, de Almeida JÚNIOR, de nosso queridíssimo e inesquecível JoÃo BATISTA DE OLIVEIRA e COSTA JÚNIOR.

Mas quanta diferença no ambiente que cerca cada uma destas solenidades, quanto progresso, quanta evolução! 
Certamente problemas existem, bem antigos, que vêm se prolongando através dos tempos, e ainda não solucionados, como o da idade mínima para o casamento, o de revelar ou não a uma criança que é filha adotiva, o da idade mais próxima para a emancipação, os delicadíssimos problemas relativos à interdição, as dificuldades ainda não definitivamente solucionadas relativas a investigação de paternidade, ao lado de problemas novíssimos que desafiam a argúcia de jovens talentosos como este que acaba de tomar posse na presente solenidade.

A medicina e o direito, têm muitos lances que os aproximam, tornando necessária uma convivência maior e mais permanente troca de idéias.

Para mencionar apenas alguns dos desafios que afligem o homem de hoje: o da inseminação artificial homóloga ou heteróloga. Já ocorreu nos Estados Unidos o fato de mulheres de militares em postos de batalha serem fecundadas com sêmen de seus maridos mantido congelado, tendo comovido o mundo inteiro o caso de um cidadão, acometido de enfermidade incurável cuja mulher foi por essa forma inseminada, vindo a dar à luz depois de mais de um ano do falecimento do marido. 